\title{
BIO. ERITROPOETINA E CONTROLE DA QUALIDADE: NOVAS ABORDAGENS ANALÍTICAS PARA ANTIGAS LIMITAÇÕES DOS BIOENSAIOS.
}

Melissa Chamon Alves Premazzi1 ${ }^{1}$; Eduardo da Silva Gomes de Castro ${ }^{1}$; Alessandra Santos Almeida ${ }^{1}$; Camila Faia de Sá1; Ingrid Pinheiro de Medeiros ${ }^{1}$; Daniel da Silva Guedes Junior ${ }^{1}$; Igor Barbosa da Silva ${ }^{1}$; Katherine Antunes de Mattos $^{1}$.

${ }^{1}$ Bio-Manguinhos.

INTRODUÇÃO A Alfaepoetina ${ }^{\circledR}$ produzida pelo Instituto de Tecnologia de Imunobiológicos (Bio-Manguinhos) tem seu processo de produção compartilhada com o Centro de Imunología Molecular (CIM/Cuba) através da transferência tecnológica do produto. Dentro do controle da qualidade, a potência é um ensaio crucial para demonstrar a efetiva relação entre a resposta clínica e a atividade biológica da eritropoetina, sendo o bioensaio em camundongos normocitêmicos a metodologia preconizada pela monografia do produto. Porém, a personalização do produto com o alto teor do estabilizante, a albumina sérica humana (HSA), nos lotes formulados restringe análises químicas de caráter investigativo do produto final.

OBJETIVO De modo a investigar lacunas entre potência biológica e análise quali/quantitativa da Alfaepoetina ${ }^{\circledR}$, o DEQUA investiu na busca de autossuficiência de conhecimento de técnicas ajustáveis ao produto, iniciando uma abordagem multidisciplinar para o controle da qualidade baseado em análises de potência biológica e físico-químicas.

METODOLOGIA Análise comparativa entre dados de bioensaios realizados no CIM e Bio. Estudo molecular do ingrediente farmacêutico ativo (IFA) e nas diferentes apresentações do produto final a partir de adequações de métodos físico-químicos validados pelo LAFIQ, utilizando os parâmetros técnicos controlados pelo uso do material de referência desenvolvido em estudo colaborativo (Bio/CIM/INCQS). Avaliação da metodologia por cromatografia a líquido de alta eficiência (CLAE-FR) como técnica quantitativa e preparativa para ensaios de mapeamento peptídico, integridade da molécula e análise de isoformas, características diretamente relacionadas com a potência biológica. 
RESULTADOS A quantificação seletiva do principio ativo de Alfapoetina na presença da HSA foi padronizada e validada conforme as especificações da USP, sendo considerada aplicável a rotina do controle de qualidade. Esta metodologia pode ser utilizada como etapa preparativa para outras análises de caráter qualitativo aplicáveis ao produto como perfil peptídico, análise de isoformas e integridade.

CONCLUSÃO A qualidade e consistência do controle lote-alote em diferentes apresentações do produto reforça que possíveis variações no valor declarado pelos bioensaios podem ser um reflexo da variabilidade e complexidade dos ensaios in vivo. A capacidade de quantificar e caracterizar a eritropoetina em qualquer etapa da produção, fortalece o conhecimento e integração de parâmetros do processo produtivo, abrindo caminho para outras frentes investigativas pertinentes à identificação de possíveis alterações intrínsicas de potência biológica. A customização deste trabalho reflete o compromisso de Bio-Manguinhos com o controle da qualidade de seus produtos, além de exercer sua contribuição científica com um novo olhar sobre a avaliação integrada do produto baseado nas interfaces, permitindo maior valorização de novos métodos físicoquímicos que possibilitem a substituição progressiva do uso de animais em bioensaios.

PALAVRAS-CHAVE eritropoetina, alfaepoetina, cromatografia, potência. 